\title{
Explicit-implicit Distinction: A Review of Related Literature
}

\author{
Marwan A. Jarrah \\ University of Jordan, Jordan \\ \& \\ Newcastle University, UK \\ Emails: m.a.s.jarrah@ncl.ac.uk; masaljarrah@yahoo.com
}

Doi:10.7575/aiac.alls.v.7n.1p.175

URL: http://dx.doi.org/10.7575/aiac.alls.v.7n.1p.175
Received: 23/09/2015

Accepted: 05/12/2015

\begin{abstract}
This paper sketches out the main views of the major pragmatic approaches (i.e., Grice's theory of conversation, Relevance Theory, and Neo-Gricean pragmatic theory) on explicit-implicit distinction. It makes clear how this distinction has been differently drawn for utterance interpretation. Additionally, it highlights several corresponding problems that have arisen within such approaches. It demonstrates ultimately that no consensus has been reached on the dividing lines of the dichotomy of this distinction.
\end{abstract}

Keywords: explicit-implicit distinction, Grice's theory of conversation, Relevance Theory, Neo-Gricean pragmatic theory

\section{Introduction}

Explicit-implicit distinction (E-ID) has recently emerged as one of the pressing issues in contemporary pragmatic theory as well as truth-conditional semantics (see, e.g., Carston 1998 Burton-Roberts 2005, and Dew and Cabeza 2011). When comparing views on E-ID, one finds that there has been no general agreement within the major pragmatic approaches regarding the precise nature of E-ID. For example, semantics vs. pragmatics was isomorphic for Grice with explicit vs. implicit (cf. Burton-Roberts 2006, Attardo 2011, and Blakemore 2014, among others). Differently, for Relevance Theory (RT) (Sperber and Wilson 1986a, 1987a,b, 1995, 1998a, 2002 and subsequent work) pragmatic enrichment has been proven essential to recovery of explicit content, an inherent combination of both linguistically-encoded and contextually-inferred conceptual components (Carston 2002, 2008, Braseth 2010, Carston and UCHIDA 2012, Clark 2013, and Wilson and Sperber 2015).

Following this, the current paper reviews some monumental works that attempt to define this two-way distinction. It capitalises on the issue how this distinction has been formulated in various pragmatic approaches, highlighting their corresponding problems relevant to this distinction. It reflects that the differences between pragmatic approaches under discussion are significant. Some have assumed that E-ID follows naturally from language use, while others argue that it is a philosophical artefact and vacuous projection of Grice's theory of conversation whose theory-internal problems and inevitable complications are incontrovertible (cf. Levinson 2000, Atlas 2005, Horn 2006, and Erdelyi 2012).

This review is organised as follows. Section 2 introduces an outline of Grice's perspective on E-ID. It poses, at the same time, two problems against Grice's: the total significance of an utterance and the unobserved overlap between A-saying and B-saying. Section 3 discusses E-ID within RT, the current dominating pragmatic practice. It also addresses some problems against RT's treatment of E-ID, including the definition of 'explicature'. Section 4 sheds light on Bach's impliciture. It explores in brief neo-Griceans' assumptions on Grice's circle and hence their call to decline E-ID. Section 5 concludes the review.

\section{Grice's E-ID and problems}

\subsection{Grice's treatment of E-ID}

Grice's invaluable views on speaker meaning and, particularly, his theory of implicatures have considerably influenced contemporary pragmatics (Wilson and Sperber 1981: 155). He pioneered a systematic way of distinction between semantics and pragmatics whose actual character and interaction with other linguistic modules were in retrospect messy and far from clear. This systematisation was carried out through a list of dichotomies, parallel ways of bridging the gap between linguistic meanings and what-is-otherwise-communicated (Hadley 1995, Yus 1999, Burton-Roberts 2005, and Ifantidou 2014). Consider the following incomplete list of dichotomies in table 1: 
Table 1. Semantics vs. pragmatics within Grice's theory of conversation

\begin{tabular}{l|l}
\hline Semantics & Pragmatics \\
\hline What is said & What is implicated \\
\hline Explicit & Implicit \\
\hline Context-free & Context-sensitive \\
\hline Truth-conditional & Non-truth-conditional \\
\hline
\end{tabular}

Semantics vs pragmatics is equated with saying vs. implicating on one hand and with explicit vs. implicit on the other (Burton-Roberts 2006). Here, what is semantically-encoded is primarily determined by what-is-said, which in turn involves conventional meanings of the words forming the given utterance and its truth-conditional propositional content

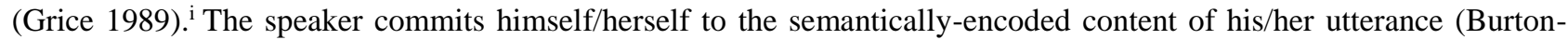
Roberts 2013). On the other hand, what is implicated cannot be captured by truth-conditional values and, as such, belongs to the realm of pragmatics (Mey 2009). For Grice, the speaker does not commit himself/herself to any nontruth-conditional meanings, which are termed as implicatures. Implicatures are defined as meanings communicated by an utterance with the exclusion of what is said. This being the case, implicatures correspond to the implicit part of E-ID. They are not purely semantically-driven but inferences derived from the explicit content of what is said in addition to some specific assumptions made available by the co-operative nature of ordinary verbal interaction (Levinson 1983). ${ }^{\text {ii }}$ Within this treatment of meanings, implicatures do not come out as rigid in nature but are classified into two broad types, namely conversational implicatures and conventional implicatures. ${ }^{\text {iii }}$ Consider figure 1 , illustrating Gricean typology of speaker's meaning (adapted from Levinson 1983).

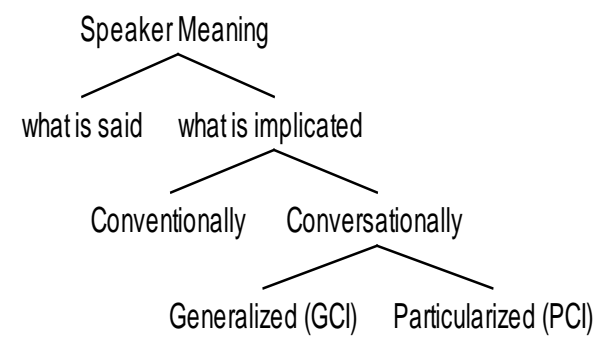

Figure 1. Gricean typology of speaker meaning

In order to differentiate between conversational and conventional implicatures, Grice isolates five properties of the former, i.e., defeasibility (or cancellability), non-detachability, calculability, non-conventionality, and variability (Levinson 1983). Implicatures are defeasible in the sense that it is possible to withdraw an implicature within utterance context, and the speaker does not contradict himself/herself. Consider utterance (1), where the implicature is withdrawn, but the utterance holds no contradiction.

(1) Some women were drunk indeed all.

Conversational implicatures are non-detachable to certain expressions, given that expressions that share similar meanings can trigger same implicatures as in (2), where both expressions: beautiful and a real beauty rise the same ironical implicature (Sadock 1978: 287):

(2) a. She is beautiful.

b. She is a real beauty.

Calculability means that implicatures can be worked out on the basis of contextual clues and Grice's Cooperative Principle and its accompanying maxims (Blome-Tillmann 2013). Non-conventionality, in turn, indicates that implicatures are not part of the conventional meaning of expressions (Noveck 2001). Variability maintains that there are contexts where the speaker utters the same utterance, but the respective implicature does not arise. Relevant to our exposition is the notion that conversational implicatures are subdivided into two types: the Generalised Conversational Implicature (GCI) and the Particularised Conversational Implicature (PCI). The main differences between these two types lie in the role of context in recovering them and the linguistic forms they appeal to. Associating highly with certain linguistic forms, including scalar elements, and relative context-independence are of the prominent properties of GCIs (Grice 1989: 37). By contrast, PCIs are context-dependent with lesser association with linguistic forms (Levinson 1983: 132). In order to appreciate this difference, consider the following example (adapted from Levinson 2000: 17)

(3) Speaker A: Where's John?

Speaker B: Some of the guests are already leaving.

GCI: Not all of the guests are already leaving.

PCI: Perhaps John has already left.

The GCI is derived by the scalar relation between all and some, whereas the PCI is determined by certain information sensitive to the specific context of the dialogue. For Grice, GCIs and PCIs are both implicitly-generated even if the 
former is less affected by particularities of the context of the relevant utterance (cf. Levinson 2000 and Schwenter 2014).

On the other hand, conventional implicatures are neither variable nor cancellable. Additionally, they are hypothesised to be detachable to certain expressions, including but, however, etc. (Grice 1975 and Potts 2003). Consider the following example, where but is replaced by and that exhibits the same truth-conditional values, but the respective implicature with the conflict interpretation does not arise.

(4) a. She is pregnant, but she is not married.

b. She is pregnant, and she is not married.

Although conventional implicatures are context-independent, stable, non-cancellable aspect of meaning, they are for Grice part of the implicit import of utterances. The pivotal point is that they are non-truth-conditional (Grice 1989 and Bach 1999b). Following this line of thought, Gricean pragmatics is said to incorporate non-truth-conditional meanings in the sense that speaker meaning is calculated with the exclusion of the truth-conditional.

However, this analysis of E-ID had not passed unchallenged. Several works highlighted aggravation of this treatment of E-ID. In the following subsections, two major problems pertaining to this treatment, namely Total Significance of an Utterance and A-saying vs B-saying are addressed. (Section 4 addresses another problem related to Grice's treatment of E-ID, namely Grice's circle),

\subsection{Problems of E-ID in Grice's}

\subsubsection{Total Significance of the Utterance}

For Grice, E-ID is not exhaustive; he introduces the notion of Total Significance of an Utterance (TSU) (Gibbs 1984:279). TSU underlies that speaker meaning is determined by adding what is said (the explicitly-decoded meaning) to what is implicated (the implicitly-communicated meaning). This addition is important so as to pin down exactly what the speaker means (i.e., TSU). Consider Figure 2 which illustrates how TSU is calculated for the utterance 'Mary has five cats'.

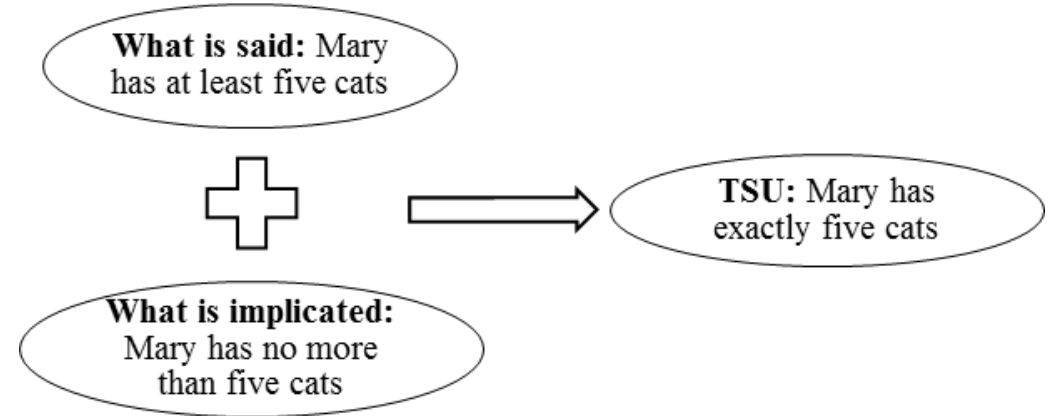

Figure 2. TSU for 'Mary has five cats'

The obligatorily-ordered addition entails that what is implicated (pragmatics for Grice) occurs after what is said (semantics), i.e., pragmatics is post-semantics. Yet, many researchers have maintained that dependence of pragmatics on semantics is risky and even perplexing and erroneous (cf. Wilson and Sperber 1981, Carsten 2002 inter alia). Such works argued convincingly that TSU does not operate in loose/figurative uses which are difficult to accommodate within this way of meaning determination. In metaphorical interpretation, pragmatics is argued to displace semantics altogether since the latter does not play any role in deciding on speaker meaning. Consider utterance (5) (a widely-used expression in Jordan).

(5) The man is a whale.

In (5), the speaker does not mean that the man is really a whale (a giant sea creature), but he/she communicates that the man is a charismatic person who energetically manages everything around him. Here, pragmatics debunks semantics rather than follows it. The same observation can be extended to irony, meiosis, and hyperbole (cf. Sperber and Wilson 1981: 160, Partington 2007, and Hall 2013). If such is the case, what is implicitly communicated might exhaust entirely what is explicitly encoded. This argument has been further taken by some as evidence against the explicit side of E-ID (Gibbs 2002). By the same token, there is increasingly emerging evidence that hearers do not first compute the literal meaning, then the nonliteral (implicit) meaning, but that they arrive at the latter earlier or in a parallel fashion (cf. Recanati 1995, Giora 2003, and Mazzarella 2015). Such assumptions render TSU's framework and the reasoning behind it, in general, and the issue whether we are dealing with explicit communication, in particular, vulnerable for refutation. Several studies (e.g., Sperber and Wilson 1986a, 1995, 1998a, 2002, and Carston 2009) have maintained that with adoption of TSU to understand speaker's meaning, the task for (better) exploration of loose/figurative uses is a large and disconcerting undertaking whose implementation is obscure at best.

\subsubsection{A-saying vs. B-saying}

Burton-Roberts (2005) argues that Grice's notion of what is explicitly communicated is not well-argued, and it is inherently problematic (2005:390-1). Burton-Roberts states that there are two distinct types of what is explicitly 'said': A-saying and B-saying. A-saying (Saying of P) is merely a quotation of the speaker's utterance, ${ }^{\text {iv }}$ while B-saying 
(Saying that $\mathrm{P}$ ) is an assessment of the thought, one intends to explicitly communicate. Burton-Roberts (2005:390) makes use of the following example to explain the difference between these two different types of sayings:

(6) It is twelve:

a. 'It is twelve' [SAYING-OF-'P']

b. It was twelve o'clock [SAYING-THAT-P]

c. It was midday [SAYING-THAT-P]

d. There were twelve men in the cricket team [SAYING-THAT-P]

e. $\quad$....

When the speaker says exactly what was said without any modification, what is said then is A-saying (like 6a). Any modification even partial to what was said is a type of B-saying (as in $6 \mathrm{~b}, \mathrm{c}, \mathrm{d}$ ). A-saying and B-saying are in clear contrast with what isn't said, i.e., what is implicated. Along similar lines, Carston (2002) argues that since Grice failed to detect the inherent differences between these two types of sayings, he did not observe the pragmatic mechanisms involved in determining B-saying, which needs a lot of pragmatic work to resolve, including reference assignment and disambiguation. Thus, Grice did not recognise pragmatic intrusion into explicit content of utterances. This lack of recognition is supposedly caused and exacerbated by heavy attention paid to pragmatic contribution to the implicit import (Huang 2007: 189). Most importantly, failure in detecting differences between A-saying and B-saying on Grice's part motivated other pragmatic approaches, most notably RT, to re-construct totally E-ID (Wilson and Sperber 2002: 260-1).

\section{RT's E-ID and problems}

\subsection{RT's account of E-ID}

In RT, every utterance has a variety of possible interpretations which are basically combinations of explicit content, context and implied meaning (Wilson and Sperber 1998:285). Although RT concedes that a borderline between explicit content and implicit import of utterances must be drawn, RT abstracts away from Gricean views on E-ID. RT exponents argue that explicit content is not equated with linguistically-decoded meaning. In addition, for them all pragmaticallyinferred processes are not constrained to the implicit import of utterances (Carston 2002). ${ }^{\mathrm{v}}$

To begin with, RT hypothesises that the first part of E-ID (i.e., explicit) is not fully determined by what is linguistically decoded but also by what is pragmatically (contextually) inferred into the conventional, truth-conditional content meaning. By contrast, the second part of E-ID (i.e., implicit) is solely derivable via pragmatic inference (Huang 2007). In order to capture the explicit side of E-ID in RT, the term 'explicature' is innovatively coined. It is motivated by the assumption that the explicit side which is majorly represented in semantic representation (or logical form, Carston 2002: 57) is typically not fully propositional. Sperber and Wilson (1986) originally indicated that the logical form does not exhibit a fixed truth condition but, rather, consists of incomplete conceptual representation which functions as a schema for pragmatic construction of propositional forms (Carston 2004:633). The distinction between explicit-implicit propositions is spelled out as follows (Carston 2002: 124).

(7) a. An assumption (proposition) communicated by an utterance is an 'explicature' of the utterance iff (i.e., if and only if) it is a development of (a) a linguistically encoded logical form of the utterance, or of (b) a sentential sub-part of a logical form. ${ }^{\mathrm{vi}}$

b. 'Implicature': An ostensively communicated assumption that is not an explicature; that is, a communicated assumption which is derived solely via processes of pragmatic inference. ${ }^{\mathrm{vii}}$

Since explicatures are developments of the logical form which they contain as a proper subpart, they flesh out the given linguistically-incomplete logical form of an utterance, which results in a fully propositional content (Huang 2007: 189). Here, the speaker commits himself/herself to the explicature of his /her utterance (Carston 2002:123). This so being, implicatures are no longer derived from Grice's Cooperative Principle and its concomitant maxims. Given the negative definition of implicature in relation to explicatures, implicatures are everything which is communicated excluding explicatures. The speaker does not commit himself/herself to any implicatures derived by his/her utterance.

Consequently, the explicature-implicature distinction constitutes an exhaustive and mutually exclusive division of communicated assumptions (Burton-Roberts 2005: 398). RT undertakes that explicatures are derived by enriching conceptual representations into propositional forms in five areas: disambiguation, reference resolution, saturation, free enrichment, and ad hoc concept construction (Carston, 2004: 633). For instance, before determining the explicit content of utterance (8), one must first disambiguate the meaning of the word 'bat' (an animal or a stick) and assign an appropriate contextual value to the referential expression included (i.e., she).

(8) She saw a bat.

The potential explicatures for utterance (8) are 'Vicky saw a baseball bat', 'Mary saw a bat (an animal), and so on and so forth. These undetermined explicatures derived gives rise to what Carston (2002:57) labels as 'Underdeterminacy Thesis'. This concept maintains that linguistic meaning underdetermines what is said; the natural language expressions fall short of encoding (Burton-Roberts 2005: 398). In utterance (9) below, the proposition is partially disallowed by ellipsis which is, in turn, difficult to unpack since the un-encoded elements must be firstly provided. 
(9) France is worse (than what?)

Given linguistically-encoded meanings are necessarily incomplete, pragmatics makes essential contribution not only to construction of implicit meanings but also to that of explicit meanings (Carston 2004: 633). ${ }^{\text {viii }}$ In relation to this, linguistic semantics (non-truth-conditional) is differentiated from real semantics (truth-theoretic, fully propositional), which both stand for the explicit side of E-ID. ${ }^{\text {ix }}$

It is revealing that RT treats conventional implicatures as explicit, and non-truth-conditional meanings are inseparable part of linguistic semantics which comes as two kinds: conceptual vs. procedural (see, Blakemore 1992, Rouchota and Jucker 1998, Ramos 1998, Fraser 2006, and Al-Jarrah et al 2015). Since conventional implicatures are detachable to certain expressions, RT argues that such expressions are linguistically-encoded instructions to the hearer, guiding him/her to Optimal Relevance (Wilson and Sperber 1993:13-8). ${ }^{\mathrm{x}}$

Again, the relevance-theoretical approach to E-ID has received criticisms and controversies. In the following subsection, some of these criticisms are highlighted and discussed.

\subsection{Problems of E-ID in RT's}

\subsubsection{Definition of explicature and development}

E-ID in the eyes of RT is not without its internal problems. Actually, most of these problems follow from the controversial definition of explicature in relation to implicature (Bird 1997, Capone 2009, and Chaves 2010, inter alia). Burton-Roberts (2005) argues that RT 'allegations' on explicatures are intrinsically dubious and difficult to fathom. He argues that explicatures are in RT totally defined in terms of development from the logical form although the notion of development is on its own a black hole at the centre of RT. That is because no clear definition for development has been introduced. This comes at price, given that lack of clear definition for development impugns the entire notion of explicatures. Burton-Roberts (2005) illustrates that if Carston's (1988) Independence Principle is adopted for the definition of development, a number of intriguing problems related to determining explicatures are unavoidable. In terms of this principle, a communicated proposition is a development of the encoded logical form of an utterance (and thus explicated) iff that proposition (asymmetrically) entails the logical form. Such a definition of development in terms of entailment leaves us, Burton-Roberts argues, impotent to two problematic notions: some implicatures cannot be cancelled, whereas explicatures can be cancelled.

\subsubsection{Non-cancellable implicatures}

Defining explicatures in RT is still contingent on what is encoded despite the fact that former is not isomorphic with the latter (Burton-Roberts 2005:397). Consider the following utterances:

(10) a. The mayor is my mother.

b. The mayor is a female.

Depending on the definitions of explicatures and implicatures and Carston's (2002) discussion on development, (10b) is hardly treated as an explicature to utterance (10a) since utterance (10b) does not entail utterance (10a) (a female $\sim$ my mother). Hence, in terms of RT, (10b) is inescapably an implicature. However, when the speaker cancels this implicature, he/she inevitably contradicts himself/herself:

(11)*The mayor is a female, indeed a male.

Actually, non-cancellability of implicatures is a less promising not trivial issue which contradicts the generally-agreedupon rule that implicatures are pragmatic inferences and thence cancellable. Non-cancelability follows plainly from putative complementarity between implicature and explicature. The former depends on the latter to determine, which in turn depends on development whose nature is not that clear and might be illicit (Burton-Roberts 2005:399). BurtonRoberts (2005) postulates that utterances like (10b) must be explicatures because they exhibit 'constitutive truthconditional content' of (10a). He states that to approach the problem of non-cancellability of implicatures, the rule of 'truth-conditional content of an EXPLICATED proposition is EXPLICATED' must be adopted. If not, he argues, all of the truth-conditional content of the explicature is treated as an implicature (Burton-Roberts 2005).

\subsubsection{Cancellable explicatures}

Given both notions that explicatures are not fully decided by what is linguistically decoded but also by what is contextually inferred into the conventional, truth-conditional content and the significant notion that pragmatic inferences are defeasible, explicatures must be cancellable (Burton-Roberts 2005:400). Carston (2002:138) concedes that explicatures are cancellable in RT. She argues that this property barely rebuts the notion of explicature because RT rejects, by definition, cancellation as a criterion for defining explicatures. Instead, explicatures in RT dwell on speaker's commitment towards what he/she endorses (Carston 2002:123). As a result, RT disbands Grice's idea of GCIs and treats them as real explicatures. However, Burton-Roberts (2005) assumes that depriving explicatures of cancellation as a criterion is untenable. He argues that one cannot cancel what he/she commits himself/herself to without contradicting himself/herself. Additionally, all explicatures would have been treated as implicatures in negative utterances. Consider the following:

(12) a. I have had breakfast (logical form). b. I have had breakfast today (explicature).

(13) a. I have not had breakfast (logical form). b. I have not had breakfast today (implicature). 
(12b) is an explicature because it entails (12a), the logical form. However, (13b) is an implicature only because it is not an explicature to (13a) not because of logical form in (13a) but because of negation. For several researchers, RT's treatment of E-ID puts blinder on what should be the truth, the veritable assumption providing the impetus for them to recast RT's treatment of E-L/D.

\section{Bach's impliciture and the Neo-Cricean's call to reject E-ID}

In this section, Bach's impliciture and the call made by researchers working within Neo-Gricean pragmatic theory to decline E-ID are briefly addressed.

\subsection{Bach's impliciture}

Problems of explicature, among others, derive some pragmatists to decline RT's treatment of E-ID. One prominent example is the so-called Bach's impliciture. Bach (1994, 1999a, 2006, and 2013) criticises the notion of explicature for its theory-internal problems and proposes, instead, the term 'impliciture'. Bach reports that there is no explicit communication but two distinct kinds of communicated proposition which are both implicit: the standard Gricean implicatures and 'implicitures' which are defined as communicated propositions that are 'implicit in what is said'. Consider the meanings of the mother's utterance in (14):

(14) Child: "Shall I eat this candy?"

Mother: "It is harmful"

a. It is harmful. (What is said)

b. It is harmful to your health. (Impliciture)

c. Do not eat it! (Implicature)

However, as other proposals on E-ID, the notion of implicitures has received a load of criticism. For example, Carston (2002 and 2008) argues that demonstrative indexicals like 'she' are not assigned a specific referent at the level of impliciture, but rather at the level of what of said which comes out as a mix of encoded constraints. Additionally, what is said' has no role beyond that played by the logical form. The latter is the input to any further context-dependent pragmatic processes that are required to recover the intended utterance meaning, which yields the notion of what is said redundant and without issue.

\subsection{Neo-Gricean approach and rejection of E-ID}

Within the neo-Gricean pragmatic framework, Grice's E-ID is totally rejected, because it is not amenable to how speaker's meaning is processed (cf. Huang 2007:203). This rejection is due to the so-called 'Grice's circle', a theoryinternal problem. ${ }^{\mathrm{xi}}$ The main argument was built on the Gricean notion that pragmatics is post-semantics (Capone 2006: 646). Levinson (2000: 195) indicates that the circle is generated by pragmatic intrusion into what is semantically encoded; implicatures take their input from what is said, ${ }^{\text {xii }}$ which takes, in turn, its input from pragmatics. Resulting circularity makes the E-ID an impossible task to mark since the starting point which is needed in utterance interpretation and which is generally taken to be utterance semantics is no longer held (Capone 2006: 646). Consider Figure 3:

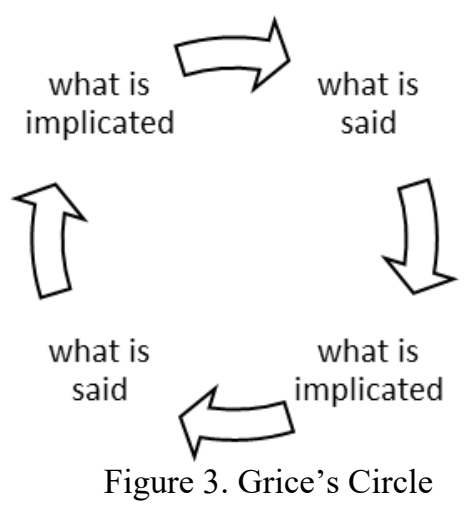

Moreover, Levinson (2000) argues that Grice gives three preconditions to determine what is said: identifying referents, fixing deictic parameters, and disambiguating the linguistic string in questions. ${ }^{\text {xiii }}$ These three preconditions espouses exactly the same inferential mechanisms which characterise Gricean Pragmatics (2000:173), an issue which has been rarely brought to the fore. For example, consider the following utterance:

(15) She is ready and she is not ready.

It is impossible to indicate whether (15) is a contradiction until the intended reference of each occurrence of she is assigned in addition to unpacking the ellipsis in each clause for ready (ready for what?). Both reference assignment and unpacking ellipsis are two contextually-sensitive processes occurring in pre-what-it-b-said, not post-semantics. For Neo-Gricean, not only does presence of E-ID obfuscate speaker meaning but also appears as an obstacle for utterance processing (cf. Shenghuan 1994, Horn 2006, Huang 2009, 2015, and Capone et al 2015). ${ }^{\text {iv }}$ 


\section{Conclusion}

This essay encapsulated what many prominent pragmatic approaches think of E-ID. For Grice, the explicit content of an utterance is isolated from the implicit import of that utterance. Some main differences between semantics and pragmatics were spelt out by virtue of this distinction. On the other hand, for RT, Grice's views on the E-ID were rejected and replaced by the distinction between explicature and implicature. In addition, this paper emphasised some problems related to these two perspectives: A-saying vs. B-saying, and TSU for the former, whereas cancellability of explicatures, and non-cancellability of implicatures for the latter. It also shed light on Grice's circle and Bach's impliciture. In general, it is clear that the E-ID cannot be a clear-cut division, thanks to unavoidable pragmaticssemantics interface.

\section{References}

Al-Jarrah, R. S., Abu Dalu, A. M., and Jarrah, M. (2015). 'A Relevance-Theoretical Account of Three Arabic Pragmatic Operators of Concession in a Political Discourse'. Lodz Papers in Pragmatics 11: 51-76.

Alhaisoni, E., Jarrah, M. A., and Shehadeh, M. S. (2012). 'An investigation of evidentiality in the Arabic language'. International Journal of Linguistics, 4: 260-273.

Al-Shamari, M. R. (2015). 'Pragmatic Analysis of the Particle ваdi in Najdi Arabic'. International Journal of Linguistics, 7(2), pp-81.

Alshamari, M. R. (2015). '1 A Relevance-Theoretical Account of Three Discourse Markers in North Hail Arabic'. Studies in Literature and Language, 11(1).

Atlas, J. (2005) Logic, Meaning, and Conversation: Semantic Underdeterminacy, Implicature, and Their Interface. Oxford: Oxford University Press.

Attardo, Salvatore. (2011). the violation of Grice's maxims in jokes. In Annual Meeting of the Berkeley Linguistics Society (Vol. 16).

Bach, K. (1994) 'Conversational impliciture'. Mind and Language 9: 124-162.

Bach, K. (1999a) 'the myth of conventional implicature'. Linguistics and Philosophy 22: 367-421.

Bach, K. (1999b) the semantics-pragmatics distinction: What it is and why it matters. In Turner, K. (ed.) the Semantics-Pragmatics Interface from Different Points of View. Oxford: Elsevier. 65-84. URL: http://online.sfsu.edu/ kbach/spd.htm.

Bach, K. (2006). The top 10 misconceptions about implicature. Drawing the Boundaries of Meaning: Neo-Gricean studies in pragmatics and semantics in honour of Laurence R. Horn, 21-30.

Bach, K. (2013). L3. Conversational impliciture. The Semantics-Pragmatics Boundary in Philosophy, 284.

Bird, G. H. (1997). Explicature, impliciture, and implicature. In Pragmatik (72-91). VS Verlag für Sozialwissenschaften.

Blakemore, D. (1992) Understanding Utterances: An Introduction to Pragmatics. Oxford: Blackwell.

Blakemore, D., and Gallai, F. (2014). 'Discourse markers in free indirect style and interpreting'. Journal of Pragmatics, 60, 106-120.

Blakemore, Diane. (2014). Linguistic form and pragmatic interpretation: the explicit and the implicit. The Pragmatics of Style (RLE Linguistics B: Grammar), 28.

Blome-Tillmann, M. (2013). 'Conversational implicatures (and how to spot them)'. Philosophy Compass 8: 170-185.

Borg, E. (2013) Minimalism versus Contextualism in semantics. In, Ezcurdia, M., and Stainton, R. (Eds.). The Semantics-Pragmatics Boundary in Philosophy. Broadview Press.

Braseth, J. (2010) Relevance theory and the problem of content sharing. Unpublished MA thesis. Universitetet I Oslo.

Brown, P. and Levinson, S. (1987) Politeness. Cambridge: Cambridge University Press.

Burton-Roberts, N. (2006) 'Cancellation and intention'. Newcastle Working Papers in Linguistics 12(13). 1-12.

Burton-Roberts, N. (2013) 'On Grice and cancellation'. Journal of Pragmatics 48(1). 17-28.

Burton-Roberts, N. (2005) 'Robyn Carston on semantics, pragmatics and 'encoding'. Journal of Linguistics 41. 389407.

Capone, A. (2006) 'On Grice's circle: a theory-internal problem in linguistic theories of the Gricean type'. Journal of Pragmatics 38: 645-669.

Capone, A. (2009). 'Are explicatures cancellable? Toward a theory of the speaker's intentionality'. Intercultural Pragmatics 6: 55-83.

Capone, A., Allan, K., Cummings, L., Davis, W., Douven, I., Sorbonne, F., and Zielińska, D. (2015). Perspectives in Pragmatics, Philosophy and Psychology. 
Carston, R. (2004) Relevance theory and the saying/implicating distinction. Handbook of pragmatics. Oxford: Blackwell. 633-656.

Carston, R. (1998). Pragmatics and the Explicit and Implicit Distinction. University College London Ph.D. thesis.

Carston, R. (2002) Thoughts and Utterances: The Pragmatics of Explicit Communication. Oxford: Blackwell.

Carston, R. (2008) 'Optional pragmatic processes or optional covert linguistic structure?' UCL Working Papers in Linguistics 20. 143-156.

Carston, R. (2009) 'the explicit/implicit distinction in pragmatics and the limits of explicit communication'. International Review of Pragmatics 1(1): 35-62.

Carston, Robyn, and Seiji UCHIDA (2012). Relevance theory. Routledge companion to the philosophy of language 163-176.

Chaves, J. E. (2010). Explicature, what is said, and Gricean factorisation criteria. Explicit communication, eds. Belén Soria and Esther Romero, 109-125.

Clark, B. (2013) Relevance theory. Cambridge University Press, 2013.

Dew, I. T., and Cabeza, R. (2011). The porous boundaries between explicit and implicit memory: behavioral and neural evidence. Annals of the New York Academy of Sciences, 1224(1), 174-190.

Erdelyi, M. H. Explicit and implicit memory. Springer Vienna, 2012.

Fraser, B. (2006). 'On the conceptual-procedural distinction'. Style, 40: 24.

Gibbs, R. W. (1984) 'Literal Meaning and Psychological Theory'. Cognitive science 8: 275-304.

Gibbs, R. W. (2002) 'A new look at literal meaning in understanding what is said and implicated'. Journal of Pragmatics 34: 457-486.

Giora, R. (2003) on our mind: salience, context, and figurative language. Oxford: Oxford University Press.

Grice, H.P. (1989) Studies in the Way of Words. Cambridge, Mass: Harvard University Press.

Hadley, Robert F. (1995) "The "explicit-implicit" distinction." Minds and Machines 5: 219-242.

Hall, A. (2013). Relevance theory, semantic content and pragmatic enrichment. In Perspectives on Linguistic Pragmatics (pp. 99-130). Springer International Publishing.

Hammouri, Y. M., Jarrah, M. A., and Khawaldeh, S. K. (2013). 'Intertextuality as a Tool to Determine Syntax'. International Journal of Linguistics, 5(2), 209-223.

Horn, L. (2006) the Border Wars: a Neo-Gricean Perspective. In K. von Heusinger and K. Turner (eds.), Where Semantics Meets Pragmatics. Amsterdam: Elsevier. 21-48.

Horn, L. R. (2006). The border wars: A neo-Gricean perspective. Where semantics meets pragmatics, 21-48.

Huang, Y. (2007). Pragmatics. Oxford: Oxford University Press.

Huang, Y. (2009). 'Neo-Gricean pragmatics and the lexicon'. International Review of Pragmatics 1: 118-153.

Huang, Y. (2015). 'Lexical cloning in English: A neo-Gricean lexical pragmatic analysis'. Journal of Pragmatics, 86: $80-85$.

Ifantidou, E. (2001) Evidentials and relevance (Vol. 86). John Benjamins Publishing.

Ifantidou, E. (2014). Pragmatic competence and relevance (Vol. 245). John Benjamins Publishing Company.

Leech, G. (1983) Principles of Pragmatics. London: Longman.

Levinson, S. (2000) Presumptive Meanings: The theory of Generalised Conversational Implicatures. Cambridge: MIT Press.

Levinson, S. (1983). Pragmatics. Cambridge: Cambridge University Press.

Levinson, S. C. (2000). Presumptive meanings: The theory of generalised conversational implicature. Cambridge, MA: MIT press.

Mazzarella, D. (2015). 'Politeness, relevance and scalar inferences'. Journal of Pragmatics 79: 93-106.

Mey, J. (Ed.). (2009). Concise encyclopaedia of pragmatics. Oxford: Pergamon.

Noveck, I. A. (2001). When children are more logical than adults: Experimental investigations of scalar implicature. Cognition 78: 165-188.

Obeidat, H., and Al-Jarrah, R. (2012). 'The Legal Translator a Photocopying Machine!' International Journal of Linguistics 4: 588-603

Partington, A. (2007). Irony and reversal of evaluation. Journal of Pragmatics 39: 1547-1569.

Potts, C. (2003) the logic of conventional implicatures. Unpublished Doctoral dissertation, University of California.

Ramos, F. Y. (1998). A decade of relevance theory. Journal of Pragmatics 30: 305-345.

Recanati, F. (1995) ‘the Alleged Priority of Literal Interpretation'. Cognitive Science 9: 207-32. 
Recanati, F. (2003) ‘Embedded implicatures’. Philosophical perspectives 17: 299-332.

Rouchota, V., and Jucker, A. H. (Eds.). (1998). Current issues in relevance theory (Vol. 58). John Benjamins Publishing.

Schwenter, S. (2014). Pragmatics of conditional marking: implicature, scalarity, and exclusivity. Routledge.

Shenghuan, X. (1994). 'Neo-Gricean apparatus and the negation of implicature'. Foreign Language Teaching and Research, 4.

Sperber, D. and Wilson, D. (1986) Relevance: communication and cognition. Oxford: Blackwell.

Sperber, D. and Wilson, D. (1995) Relevance: Communication and Cognition, second edition. Oxford: Blackwell Publishers Ltd.

Sperber, D. and Wilson, D. (1986a). Relevance: Communication and Cognition. Cambridge, MA: Harvard University Press. (2nd edn., 1995, Oxford: Blackwell.)

Sperber, D. and Wilson, D. (1987a). 'Précis of Relevance. Behavioural and Brain Sciences 10: 697-710.

Sperber, D. and Wilson, D. (1987b). 'Presumptions of relevance'. Behavioural and Brain Sciences 10: 736-53.

Sperber, D. and Wilson, D. (1998a). the mapping between the mental and the public lexicon. In P. Carruthers and J. Boucher (eds.), Language and Thought: Interdisciplinary Themes. Cambridge: Cambridge University Press 184-200.

Sperber, D. and Wilson, D. (2002). 'Pragmatics, modularity and mind-reading'. Mind and Language 17: 3-23.

Taha, K. T., Jarrah, M. A., and Al-Jarrah, R. S. (2014). 'The Discoursal Arabic Coordinating Conjunction Wa' (And). International Journal of Linguistics, 6: 172.

Wilson, D. and Sperber, D (1981) On Grice's theory of conversation. In Werth, P. (ed) Conversation and Discourse. Croom-Helm. 155-178.

Wilson, D. and Sperber, D (1993) Linguistic Form and Relevance. Lingua 90: 1-25

Wilson, D. and Sperber, D (1998) Pragmatics and time. Pragmatics and Beyond New Series, 1-22.

Wilson, D. and Sperber, D (Eds.) (2002). Relevance theory. UCL Working Papers in Linguistics 13. $249-287$.

Wilson, D. and Sperber, D (2002a). 'Truthfulness and relevance'. Mind 111: 583-632.

Wilson, D. and Sperber, D. (2002b). Relevance theory. In Horn, L., Ward, G. (Eds.), the Handbook of Pragmatics. Blackwell, Oxford.

Wilson, D. and Sperber, D. (2004). Relevance theory. In Horn, Laurence, and Gergory Ward. (eds.) the handbook of pragmatics. Oxford: Blackwell. 607-632.

Wilson, D. and Sperber, D. (2015) "Outline of Relevance Theory." HERMES-Journal of Language and Communication in Business 3: 35-56.

Yus, F. (1999) 'Misunderstandings and explicit/implicit communication.’ Pragmatics 9: 487-518.

\section{Notes}

${ }^{i}$ With the exclusion of any conventional implicature (Huang 2007: 178)

ii In this regard, Grice introduces the Cooperative Principle and its four accompanying maxims of communication, whose consideration or flouting creates implicatures (see, e.g., Grice 1989, Blakemore 1992, and Levinson 1983).

iii There are other kinds of implicatures, including implicature of politeness or style that are neither conventional nor conversational (cf. Leech 1983 and Brown and Levinson 1987).

iv The notion of A-saying is much observed in legal texts where the legal interpreter translates the legal texts as they are without even stating the B-saying. It is natural then to label the legal interpreter as a photocopying machine (Obeidat and Al-Jarrah 2012).

${ }^{\mathrm{v}}$ It is worth mentioning that although Grice remarked that disambiguation and reference assignment fall on the explicit rather than the implicit side, he thought of them as determined by sentence meaning and contextual factors alone, without reference to pragmatic principles or speakers' intentions (Wilson and Sperber 2002: 261).

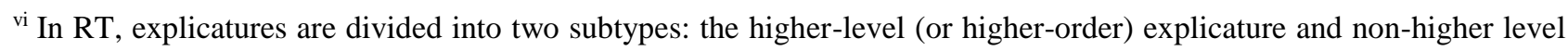
implicatures (Wilson and Sperber 2004).

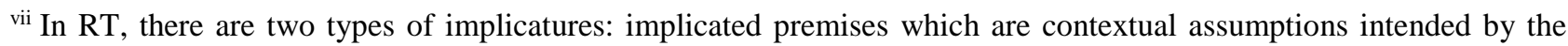
speaker and supplied by the addressee and implicated conclusions which are contextual implications communicated by the speaker (Huang 2007: 195).

viii In the relevance-theoretic account the human cognitive architecture is depicted 'according to which linguistic semantics is the output of a modular linguistic decoding system and serves as input to a pragmatic processor' (Carston 2004: 633). 
ix It is beyond the scope of this essay to discuss RT's three-level model of semantic and pragmatic interpretation of linguistic expressions or three strengths of underdeterminacy.

${ }^{\mathrm{x}}$ The Conceptual vs. procedural distinction has been a fecund soil for fruitful research. Much literature utilised this distinction to explore the functions and roles played by certain lexemes in utterance interpretation, including discourse markers (Alhaisoni et al 2012, Hammouri et al 2013, Blakemore and Gallai 2014, Taha et al 2014, Al-Jarrah et al 2015, and Alshamari 2015, Al-Shamari 2015, among others).

${ }^{x i}$ Grice's circle is also a problem for truth-conditional semantics (Capone 2006: 646).

xii This notion is supported by Recanati (2003) who explicitly states that:

'Implicatures are generated via an inference whose input is the fact that the speaker has said that $p$. Hence no implicature can be computed unless something has been said, some proposition expressed. In particular, no implicature can be computed at a sublocutionary level. We have to compute the truth-conditions first, so as to ascribe a definite content to the speaker's speech act, before we can infer anything from that speech act.(p.300)'

xiii Levinson (2000) adds other two preconditions of determining what is said: unpacking ellipsis and narrowing generalities (p. 174).

${ }^{\text {xiv }}$ Utterance (15) is in fact problematic in terms of the semantic law of non-contradiction, an utterance and its negation cannot be both true in the same situation (Borg 2013), given that the second conjunct of (15) is a negation of its first conjunct. 